\title{
EU:n sokerijärjestelmä ristitulessa - kuka kaipaa suojaa?
}

\author{
Kyösti Arovuori \\ Taloustieteen laitos, PL 2700014 Helsingin yliopisto, kyosti.arovuori@helsinki.fi
}

\section{Johdanto}

Paineet EU:n sokerijärjestelmän muuttamiseksi ovat kasvaneet voimakkaasti viime vuosien aikana. Tämä on ensisijaisesti seurausta siitä, että sokerin markkinajärjestelmä on jätetty molempien, vuosina 1992 ja 1999, toteutettujen CAP (Common Agricultural Policy) -reformien ulkopuolelle. Sokerijärjestelmää kohtaan kohdistuu paineita sekä EU:n sisäisiltä että ulkopuolisilta markkinoilta. Markkinointivuonna 2001/2002 toteutettua sokerin markkinajärjestelyn väliarviointia varten Euroopan komissio julkisti vuonna 2000 kolme mahdollista muutosehdotusta, joiden tavoitteena oli pyrkiä vastaamaan nykyistä järjestelmää vastaan kohdistuviin paineisiin. Nämä muutosehdotukset olivat: (1) sokerin kokonaiskiintiöiden leikkaaminen 13 prosenttia (Suomessa tämä tarkoittaisi noin 8 prosentin leikkausta), (2) sokerin interventiohinnan alentaminen 25 prosenttia ja näiden hinnanalennusten jaksottaminen usean vuoden ajalle, sekä (3) interventiohinnan alentaminen 25 prosenttia ja näiden alennusten kompensoiminen 50 prosenttisesti tuottajille. Esitetyistä muutosehdotuksista huolimatta EU:n sokerijärjestelmä päätettiin säilyttää ennallaan markkinointivuoden 2005/2006 loppuun saakka.

Tässä tutkimuksessa tarkastellaan näiden muutosehdotusten vaikutuksia Suomen sokerisektorilla. Politiikkamuutoksia pyritään arvioimaan kuluttajan ja tuottajan ylijäämissä (Consumer surpluss, CS ja Producer surpluss, PS) tapahtuvien muutosten kautta. Tuottajan ja kuluttajan ylijäämät on määritetty rakentamalla yksinkertaistettu Suomen sokerimarkkinoita kuvaama malli, johon on otettu mukaan kolme keskeistä muuttujaa: sokerin tarjottu määrä, sokerin kysytty määrä sekä sokerin markkinahinta.

Lisäksi pyritään saatujen tulosten perusteella arvioimaan, kuinka Euroopan komission syksyllä 2003 ehdottamat uudet muutosehdotukset toteutuessaan vaikuttaisivat Suomen sokerisektorilla. Nämä uudet muutosehdotukset ovat: (1) nykyisen järjestelmän jatkaminen siten, että tulleja, sisäisiä hintoja ja tuotantokiintiöitä alennettaisiin, (2) EU:n sisäisten hintojen alentaminen siten, että se johtaa kiintiöjärjestelmän asteittaiseen poistumiseen sekä (3) nykyisen järjestelmän täydellinen vapauttaminen.

\section{Aineisto ja menetelmät}

Tutkimusaineistona käytetään Euroopan unionin tilastoja sokerin tuotannosta ja kulutuksesta yhteisön alueella. Aineiston luotettavuutta vahvistetaan vertaamalla lukuja muihin saatavilla oleviin tilastoihin (esim. FAO). Tuotettuna (kulutettuna) määränä käytetään valkoisen sokerin Suomessa tuotetun (kulutetun) määrän keskiarvoa vuosilta 1995-2001 ja vastaavasti käytetyt hinnat ovat valkoisen sokerin hallinnolliset hinnat. Maailmanmarkkinahintana käytetään Lontoon sokeripörssin vuosien 1997-2001 keskiarvohintaa.

Tutkimuksessa on käytetty tarjonnan hintajouston arvona 0,56 , joka on aikaisemmissa tutkimuksissa estimoitujen joustojen keskiarvo. Kysynnän hintajouston arvona on käytetty $-0,15$, mikä on yhtälailla aikaisemmissa tutkimuksissa estimoitujen joustojen keskiarvo.

Taulukko 1. Aikaisemmissa tutkimuksissa estimoituja sokerin pitkän aikavälin hintajoustoja Suomessa.

\begin{tabular}{|c|c|c|}
\hline & $\begin{array}{l}\text { Sokerin tarjonnan hinta- } \\
\text { joustot }\end{array}$ & $\begin{array}{l}\text { Sokerin kysynnän } \\
\text { hintajoustot }\end{array}$ \\
\hline Kettunen \& Ryökäs (1984) & 0,34 & $-0,2$ \\
\hline Isosaari (1993) & (lyhyt aikaväli) 0,48 & $-0,15$ \\
\hline & 1,13 & \\
\hline Lahtinen (1997) & 0,52 & \\
\hline Penttilä (1997) & 0,3 & $-0,1$ \\
\hline
\end{tabular}

Sokerimarkkinoilla vallitsevaa tilannetta pyritään havainnollistamaan luomalla kysyntä-tarjontamalli. Koska tarkastelun kohteena on ainoastaan yksi tuote, on mallin muuttujiksi tarpeellista ot- 
taa ainoastaan kolme muuttujaa. Nämä muuttujat ovat tuotteen kysytty määrä $\mathrm{Q}^{\mathrm{d}}$, tuotteen tarjottu määrä $Q^{\text {s }}$ sekä tuotteen hinta $P$ (Chiang 1984, s. 36-37). Tuottajan ylijäämän oletetaan koskevan sekä tuottajia että jalostavaa teollisuutta. Hallinnollisia hintamuutoksia tarkastellaan valkoisen sokerin hinnan kautta, koska EU:n sokerijärjestelmässä juurikkaan hinta johdetaan valkoisen sokerin hinnasta.

Mallissa käytetään kysyntä- ja tarjontafunktioita, joissa tuotteen hinta P määräytyy tuotetun määrän Q funktiona (vrt. esim. Kola 1991, Isosaari 1993), eli

$$
\begin{aligned}
& \mathrm{P}^{\mathrm{d}}=\mathrm{D}(\mathrm{Q}) \\
& \mathrm{P}^{\mathrm{s}}=\mathrm{S}(\mathrm{Q})
\end{aligned}
$$

Hyvinvointivaikutusten määrittämiseksi tarjonta- ja kysyntäkäyrät oletetaan lineaarisiksi, koska se on empiirisen tutkimuksen kannalta yksinkertaisinta (Tomek ja Robinson 1990, s. 59). Lineaariset kysyntä- ja tarjontakäyrät ovat muotoa

$$
\begin{array}{ll}
\mathrm{P}^{\mathrm{d}}=\mathrm{a}_{0}+\mathrm{a}_{1} \mathrm{Q}_{\mathrm{d}}, & \text { jossa } \mathrm{a}_{1}<0 \\
\mathrm{P}^{\mathrm{s}}=\mathrm{b}_{0}+\mathrm{b}_{1} \mathrm{Q}_{\mathrm{s}}, & \text { jossa } \mathrm{b}_{1}>0
\end{array}
$$

Tästä seuraa, että oletus laskevasta kysyntäkäyrästä ja nousevasta tarjontakäyrästä on voimassa, eli $\mathrm{D}^{\prime}(\mathrm{Q})<0$ ja S'(Q) $>0$ (Chiang 1984, s. 38-39).

Kuluttajan ja tuottajan ylijäämän määritelmän perusteella saadaan, että

$$
\mathrm{Q}
$$

$$
\mathrm{PS}=\mathrm{S}(\mathrm{Q}) \mathrm{Q}-\underset{0}{\mathrm{Q}} \mathrm{\int}(\mathrm{Q}) \mathrm{dQ} \text {. }
$$

Sijoittamalla yhtälö (3) yhtälöön (5) ja yhtälö (4) yhtälöön (6) saadaan

$$
\begin{gathered}
\mathrm{CS}=\int_{0}^{\mathrm{Q}}\left(\mathrm{a}_{0}+\mathrm{a}_{1} \mathrm{Q}\right) \mathrm{dQ}-\left(\mathrm{a}_{0}+\mathrm{a}_{1} \mathrm{Q}\right) \mathrm{Q} \\
\mathrm{PS}=\left(\mathrm{b}_{0}+\mathrm{b}_{1} \mathrm{Q}\right) \mathrm{Q}-\int_{0}^{\mathrm{Q}}\left(\mathrm{b}_{0}+\mathrm{b}_{1} \mathrm{Q}\right) \mathrm{dQ} . \\
0
\end{gathered}
$$

\section{Tulokset}

Tarkastelu on jaettu kahteen osaan. Ensimmäiseksi on tarkasteltu tuotantokiintiöiden leikkaamisen aiheuttamia vaikutuksia tuottajan ja kuluttajan ylijäämiin. Toiseksi on tarkasteltu hallinnollisten hintojen leikkaamisesta aiheutuvia muutoksia tuottajan ja kuluttajan ylijäämiin sekä näiden hinnan alennusten kompensoimista 50 prosenttisesti tuottajille. Lähtökohtaisena oletuksena on, että Suomessa on korkeiden tuotantokustannusten seurauksena kannattavaa tuottaa sokeria ainoastaan A-kiintiöön ja joidenkin tuottajien myös B-kiintiöön (Frandsen ym. 2003, s. 10).

Lähtötilanteessa tuottajan ylijäämä on 77 miljoonaa euroa (taulukko 2). Kiintiöiden leikkauksen seurauksena ylijäämä pienenee noin 180000 euroa. C-sokerin tuotannon osalta ylijäämä on negatiivista. Tämä tarkoittaa sitä, että C-sokerin tuotanto pienentää tuottajan ylijäämää, eli käytännössä C-sokerin tuotanto ei kata tuotannon muuttuvia kustannuksia. C-sokerin tuotanto onkin osaltaan selitettävissä varautumistekijällä, eli tuottajan voidaan olettaa pyrkivän täyttämään sokerikiintiönsä vuotuisista satovaihteluista huolimatta.

Kiintiöiden leikkaaminen siten, että B-kiintiö eliminoituu, johtaa tuottajan ylijäämän kasvuun Suomessa. Tämä on seurausta siitä, että kiintiösokerin vientitarve maailmanmarkkinoille vähenee. Vientitarpeen pienentymisen seurauksena tuottajilta perittävistä tuotantomaksuista voidaan luopua. Käytännössä tämä tarkoittaa sitä, että kaikki kiintiöity sokeri tuotetaan A-kiintiöön, eli kiintiöidylle 
sokerille on vain yksi hinta nykyisen kahden sijasta. A-kiintiöön tuotetun sokerin hinta nousee siis kaksi prosenttia ja B-kiintiöön tuotetun sokerin hinta 39,5 prosenttia. Kiintiöiden leikkaamisen ja tuotantomaksujen poistumisen seurauksena tuottajan ylijäämä nousee 82,1 miljoonaan euroon (taulukko 2).

Taulukko 2. Tuotantokiintiöiden leikkaamisen vaikutukset tuottajan ja kuluttajan ylijäämiin.

\begin{tabular}{|c|c|c|c|}
\hline & $\begin{array}{l}\text { Tonnia valkoista soke- } \\
\text { ria }\end{array}$ & $\begin{array}{l}\text { Tuottajan ylijäämä } \\
\text { (milj. euroa) }\end{array}$ & $\begin{array}{l}\text { Kuluttajan ylijäämä } \\
\text { (milj. euroa) }\end{array}$ \\
\hline \multicolumn{4}{|c|}{ Nykyiset sokerikiintiöt } \\
\hline A-kiintiö & 132806 & 75,12 & \\
\hline B-kiintiö & 13280 & 4,64 & \\
\hline C-sokeri & 2624 & $-2,34$ & \\
\hline Yhteensä & 148710 & 77,4 & 408,85 \\
\hline \multicolumn{4}{|c|}{ Uudet sokerikiintiöt } \\
\hline A-kiintiö & 122049 & 74,6 & \\
\hline B-kiintiö & 12151 & 4,60 & \\
\hline C-sokeri & 2361 & $-1,80$ & \\
\hline Yhteensä & 136561 & 77,4 & 408,85 \\
\hline Muutos & -12149 & $-0,018$ & 0 \\
\hline Muutos \% & $-8,2$ & & \\
\hline \multicolumn{4}{|c|}{ B-kiintiön poistuminen } \\
\hline A-kiintiö & 134200 & 83,9 & \\
\hline C-sokeri & 2361 & $-1,80$ & \\
\hline Yhteensä & 136561 & 82,1 & 408,85 \\
\hline Muutos & -12149 & 4,70 & 0 \\
\hline Muutos \% & $-8,2$ & & \\
\hline
\end{tabular}

Kiintiöjärjestelmä ei rajoita kulutusta EU:n sisämarkkinoilla, koska kiintiöity tuotanto on kulutusta suurempaa. Tästä seuraa, että Suomessa vallitsevasta alituotantotilanteesta huolimatta kuluttajilla on mahdollisuus saada kotimaisen tuotannon kanssa samanhintaista sokeria kysyntää vastaava määrä. Leikkauksen seurauksena kiintiöity tuotanto on tarkoitus rajoittaa EU:n sisämarkkinoiden kulutusta vastaavalle tasolle. Tästä seuraa, että kiintiöidyn tuotannon oletetaan vastaavan kulutusta myös leikkauksen jälkeen. Näin ollen kuluttajan ylijäämä säilyy nykyisellä noin 409 miljoonan euron tasolla myös uudessa tilanteessa (taulukko 2).

Hinnan alentamisen seurauksena sokerin tuotettu määrä pienenee noin 29 prosenttia ja tuottajan ylijäämä noin 30 miljoonaa euroa (taulukko 3). Hintamuutoksen jälkeen tuottajan ylijäämä on siis noin 46 miljoonaa euroa. Ylijäämässä tapahtuva muutos on seurausta sekä hinnan alentumisesta että tuotetun määrän muutoksista.

Taulukko 3. Hallinnollisten hintojen alentamisen vaikutukset tuottajan ja kuluttajan ylijäämiin.

\begin{tabular}{|c|c|c|c|}
\hline & $\begin{array}{l}\text { Tonnia valkoista } \\
\text { sokeria }\end{array}$ & $\begin{array}{l}\text { Tuottajan ylijäämä } \\
\text { (milj. euroa) }\end{array}$ & $\begin{array}{l}\text { Kuluttajan ylijäämä } \\
\text { (milj. euroa) }\end{array}$ \\
\hline \multicolumn{4}{|l|}{ Nykyiset sokerikiintiöt } \\
\hline A-kiintiö & 132806 & 75,12 & \\
\hline B-kiintiö & 13280 & 4,64 & \\
\hline C-sokeri & 2624 & $-2,34$ & \\
\hline Yhteensä & 148710 & 77,4 & 408,85 \\
\hline Hinnan alennus $25 \%$ & 106478 & 46,1 & 437,79 \\
\hline Muutos & -42232 & $-31,3$ & 28,94 \\
\hline Muutos $\%$ & -29 & & \\
\hline $\begin{array}{l}\text { Hinnan alennusten kompen- } \\
\text { sointi } 50 \%\end{array}$ & 106478 & 58,0 & 426,6 \\
\hline Muutos & -42232 & $-19,4$ & 17,8 \\
\hline Muutos \% & -29 & & \\
\hline
\end{tabular}

Kuluttajan ylijäämä on alkutilanteessa noin 409 miljoonaa euroa. Hintamuutoksen seurauksena ylijäämä kasvaa noin 29 miljoonaa euroa.. Kuluttajan ylijäämän kasvu on siis hieman pienempi 
verrattuna hintamuutoksesta tuottajille aiheutuva tappioon. Tämä tarkoittaa sitä, että hinnan alentumisesta aiheutuu yhteiskunnallista nettotappiota noin 2,4 miljoonaa euroa.

Hinnan alennuksen 50 prosenttisen kompensaation seurauksena kuluttajat korvaavat tuottajien kokemasta tappiosta noin 11 miljoonaa euroa suorien tukien kautta (taulukko 3). Kompensaation seurauksena tuottajan ylijäämä on uudessa tilanteessa noin 58 miljoonaa euroa. Suorien tukien vaikutuksia tuotettuun määrään ei pystytä tämän tutkimuksen puitteissa määrittämään. Oletuksena kuitenkin on, että suora tuki ei vaikuta tuotettuun määrän, vaan tuotetussa määrässä tapahtuva muutos on tarjontakäyrältä saatavan hintaresponssin mukainen. Tämä tarkoittaa sitä, että tuottajat optimoivat tuotantonsa siten, että tuotteesta saatava hinta kattaa tuotannon muuttuvat kustannukset.

Kompensaation seurauksena kuluttajat menettävät hinnan alennuksen seurauksena saavuttamastaan ylijäämästä 11 miljoonaa euroa. Lähtötilanteeseen verrattuna kuluttajan ylijäämä kasvaa kuitenkin vajaat 18 miljoonaa euroa (taulukko 3).

\section{Johtopäätökset}

Kiintiöiden leikkaaminen siten, että leikkaamisen seurauksena tuotantomaksut poistuvat, olisi tarkastelluista vaihtoehdoista Suomen kannalta selvästi paras. Kiintiöjärjestelmä mahdollistaisi tuotannon säilymisen lähes nykyisellä tasolla ja takaisi samalla erityisesti korkeiden tuotantokustannusten alueen tuottajille tärkeän kiintiöhyödyn. Tuottajilla olisi edelleen mahdollisuus tuottaa sokeria maakohtaista kiintiötä vastaava määrä ja täten turvata kiintiöiden säilyminen jatkossakin täysimääräisinä.

Hintojen alentaminen olisi Suomen kannalta selvästi huonompi vaihtoehto verrattuna kiintiöiden leikkaamiseen. Tuotannon taso tippuisi, eikä Suomi pystyisi enää täyttämään maakohtaisia kiintiöitään. Tämän seurauksena tuottajat menettäisivät kiintiöhyötyä selvästi enemmän verrattuna kiintiöiden leikkaamiseen, jossa hyöty osaltaan jopa kasvaa. Tämän tutkimuksen puitteissa ei ole mahdollista sanoa, kuinka hinnan alennusten kompensoiminen suorilla tuilla vaikuttaa tuotannon määrään. Oletuksena kuitenkin on, että tuotannon määrästä riippumaton tuki ei sisällä kannustinta tuotannon kasvattamiseen. Uusista muutosehdotuksista nykyisen järjestelmän säilyttäminen, vaikkakin hintoja alentamalla ja kiintiöitä pienentämällä, olisi tämän tutkimuksen tuloksiin peilattuna paras vaihtoehto. Tällöin tuottajilla olisi mahdollisuus edelleen saavuttaa kiintiöhyödyn kautta kompensaatiota korkeille tuotantokustannuksille, verrattuna markkinoiden vapauttamiseen tai kiintiöjärjestelmän asteittaiseen poistamiseen, jotka kummatkin johtaisivat suurempiin hinnan alennuksiin.

\section{Kirjallisuus}

Chiang, A. C. 1984. Fundamental Methods of Mathematical Economics. 3rd edition. McGraw-Hill Inc. 788 p. Euroopan komissio. 2000. Ehdotus Sokerimarkkinoiden muuttamisesta. Newsletter Nro 27 Lokakuu 2000. 2 s. Bryssel.

Euroopan komissio. 2003. Kestävän eurooppalaisen maatalousmallin toteuttaminen YMP:n uudistuksella tupakka-, oliiviöljy-, puuvilla- ja sokerialat. Komission tiedonanto neuvostolle ja parlamentille. 23.9.2003. KOM (2003) 554 lopullinen. Saatavilla: http://europa.eu.int/comm/agriculture/capreform/com554/index fi.htm. Viitattu 28.9.2003.

Frandsen, S. E., Jensen, H. G., Wusheng, Y. \& Walter-Jorgensen, A. 2003. Reform of EU sugar policy: price cuts versus quota reductions. European Review of Agricultural Economics 30, 1: 1-26.

Isosaari, H. 1993. Policy Choice under Imperfect Competition with an Application to the Finnish Sugar Market. Pellervon taloudellisen tutkimuslaitoksen julkaisuja N:o 14. 134 p. Espoo.

Kola, J. 1991. Production control in Finnish agriculture. Maatalouden taloudellisen tutkimuslaitoksen julkaisuja $64.133 \mathrm{p}$.

Kettunen, L. \& Ryökäs, M. 1984. Maataloustuotteiden pitkän aikavälin tarjontafunktiot. Maatalouden taloudellisen tutkimuslaitoksen tiedonantoja $105.36 \mathrm{~s}$.

Lahtinen, J. 1997. Sokerijuurikkaan kiintiöjärjestelmä ja tarjonta Suomessa. Maatalouspolitiikan Pro Gradu tutkielma. Helsingin yliopisto. Taloustieteen laitos. $66 \mathrm{~s}$. Helsinki.

Penttilä, A. 1997. Suomen EU-jäsenyyden vaikutukset tuottajien ja kuluttajien hyvinvointiin. Maatalouden taloudellisen tutkimuslaitoksen selvityksiä 9/97. 44 s.

Tomek, G. W. \& Robinson, K. L. 1990. Agricultural Product Prices. 3rd ed. 361 p. Cornell University Press. 